\title{
Horta Acadêmica e Ensino Superior a Distância: uma Experiência em um Polo Presencial no Rio de Janeiro
}

\section{Academic Garden and Distance Higher Education: an Experience in an In-Class Pole in Rio de Janeiro}

\author{
Mônica Pereira1* \\ Anderson dos Santos Portugal ${ }^{1}$ \\ Fátima Kzam Damaceno de \\ Lacerda ${ }^{1}$ \\ 1 Universidade do Estado do Rio de \\ Janeiro. Rua São Francisco Xavier, 524, \\ Maracanã - Rio de Janeiro - RJ - Brasil. \\ *monica_1980nf@hotmail.com
}

\section{Resumo}

Hortas em instituições de ensino se caracterizam como locais capazes de ampliar as relações interpessoais através da realização de atividades didáticas e de sociabilidade. Este potencial integrador pode vir a preencher lacunas relacionadas à dificuldade de o estudante se adaptar às diferenças entre os ambientes físico e virtual no ensino superior a distância. Neste contexto, o objetivo deste trabalho é relatar a experiência de elaboração e manutenção de uma horta em um polo de apoio presencial situado no estado do Rio de Janeiro e que envolveu a participação das comunidades acadêmica e externa. Foram organizadas duas oficinas com 28 estudantes e nove tutores presenciais do curso de licenciatura em ciências biológicas. Utilizaram-se questionários pré e pós atividade para coletar a opinião dos participantes sobre a ação proposta. Foi constatado que tanto os estudantes como os tutores presenciais vislumbraram a horta acadêmica como facilitadora do processo ensino-aprendizagem, embora $29 \%$ dos participantes tenham considerado difícil a sua implantação. Desta forma, a horta foi considerada uma experiência didática viável na EaD, promovendo espaços de práticas de ensino, pesquisa e extensão.

Palavras-chave: Educação a distância. Educação ambiental. Interdisciplinaridade. Mediação pedagógica.

\section{(c) (i)}

Recebido 12/03/2021 Aceito 20/07/2021

Publicado 22/07/2021

\section{COMO CITAR ESTE ARTIGO}

ABNT: PEREIRA, M.; PORTUGAL, A. S.; LACERDA, F. K. D. Horta Acadêmica e Ensino Superior a Distância: uma Experiência em um Polo Presencial no Rio de Janeiro. EaD em Foco, v. 11, n. 1, e1399, 2021. doi:https://doi.org/10.18264/eadf.v11i1.1399 


\title{
Academic Garden and Distance Higher Education: an Experience in an In-Class Pole in Rio de Janeiro
}

\begin{abstract}
Vegetable gardens in educational institutions are characterized as places capable of expanding interpersonal relationships through didactic and sociability activities. This integrative potential can help fill gaps related to student's difficulties to adapt to the differences between face-to-face and virtual environments in distance higher education. In this context, the objective of this work is to report the experience of elaboration and maintenance of a vegetable garden in an on-site support center located in the state of Rio de Janeiro, which involved the participation of the academic and external communities. Two workshops were organized with 28 students and nine in-class mediator from the Biological Sciences graduation course. Pre- and post-activity questionnaires were used to collect the participants' opinion about the proposed action. It was found that students and the face-to-face mediators saw the academic vegetable garden as a facilitator of the teaching-learning process, even though 29\% of the participants found it difficult to implement. Thus, the vegetable garden was considered a viable didactic experience in EaD, promoting spaces for teaching practices, research and extension.
\end{abstract}

Keywords: Distance education. Environmental education. Interdisciplinarity. Pedagogical mediation.

\section{Introdução}

As hortas são locais de terreno onde se cultivam diversos tipos de plantas, como temperos, ervas medicinais, flores comestíveis, entre outros. Porém, quando neste local ocorre o encontro de cultivares, questões didáticas e atividades pedagógicas, este se torna um ambiente de múltiplas aprendizagens que possui interface com o cotidiano do aluno (FERNANDES, 2009). Neste sentido, a palavra "agricultura" pode ser ressignificada de um termo definido como a "Arte de cultivar os campos" para "A prática de colher conhecimento" (ROCHA, 2009).

Em suas ambiciências, as hortas possibilitam meios de trabalhar diversas temáticas, dentre as quais, princípios históricos da agricultura e das ciências, educação ambiental, a saúde alimentar e temas transdisciplinares, como artes e matemática (CORDEIRO, COSTA e MURATA, 2014; CRIBB, 2007, 2010; MORGADO e SANTOS, 2008; SILVA et al., 2013). Ao pensar em uma horta no ensino superior, esta pode se aliar a diversas propostas curriculares, facilitar aulas práticas e de campo, disponibilizar material biológico in situ, e integrar disciplinas como botânica, zoologia, ecologia, pedologia e agroecologia (SILVA et al., 2013). Além disso, com as hortas há possibilidade de desenvolver um leque de atividades pedagógicas de pesquisa, ensino e extensão e, desta forma, colocar em prática a essência do marco civilizatório da Universidade (FORPROEX, 2012).

O espaço da horta em instituições de ensino se caracteriza como local capaz de religar pessoas aos fundamentos básicos da alimentação, atividades didáticas e de sociabilidade (CAPRA, 2005). Este potencial integrador de diálogos e de aprendizagem das hortas pode vir a contribuir na superação de dificuldades que os estudantes encontram na educação a distância (EaD) para se adaptar às diferenças entre os am- 
bientes físico e virtual, e a necessidade de reestruturação da concepção de aprendizagem como fruto da experiência (MARINO, PASSOS, MAGALHÃES, 2018), especialmente no que se refere ao ensino superior.

Trazer à tona maior vivência acadêmica e equidade na disparidade dos ambientes físicos e virtuais, para o aluno da EaD, requer diferentes conceitos e métodos associados a iniciativas e ações inovadoras, tanto de docentes quanto de estudantes (NUÑEZ, 2004). Embora muito se aborde teoricamente sobre a diminuição da diferença física e virtual na $\mathrm{EaD}$ e as questões de empatia que estas geram, não há soluções concretas para tal (MARINO, PASSOS, MAGALHÃES, 2018). Neste sentido, ampliar a possibilidade de espaço social (tanto virtual como físico) de integração deste aluno pode ser um caminho para solucionar esta questão na educação a distância.

Tendo as hortas acadêmicas como o eixo integrador sociocultural e pedagógico, estas mesmas poderiam atender o grande desafio imposto à EaD (NUÑEZ, 2004) que consiste na escolha de uma abordagem diferenciada diante das dificuldades de ambientação física e emocional? Alguns trabalhos já foram realizados com hortas em diversos níveis de ensino. No ensino infantil, por exemplo, temos o trabalho realizado por Cordeiro, Costa e Murata (2014); no ensino fundamental e médio, os trabalhos de Morgado e Santos (2008), Cribb (2007), Ortega (2008), Fernandes (2009), Kher e Portugal (2015). No Ensino Superior, na modalidade presencial, o trabalho realizado com horta agroecológica desenvolvido no Curso de Agronomia da Universidade Federal Rural de Pernambuco (SILVA et al., 2013), mas nenhum trabalho voltado para o Ensino Superior a Distância. Os trabalhos supracitados mostram resultados positivos no tema ensino-aprendizagem. Contudo, se fazem necessárias pesquisas voltadas ao Ensino Superior a Distância, para aprofundar as questões epistemológicas inerentes à sua natureza.

De modo a contribuir para essa discussão no ensino superior a distância, o objetivo deste trabalho é relatar a construção e manutenção de uma horta em um polo de apoio presencial situado no Rio de Janeiro. Nosso desafio neste artigo é entender a influência da horta acadêmica nos atores envolvidos, captar suas reverberações no polo e as consequências das ações individuais e coletivas que tangenciam o cotidiano da formação dos estudantes, especialmente nos cursos de formação de professores.

\section{Implementação da horta acadêmica em um polo de ensino superior a distância}

As atividades práticas, que envolvem a realização de duas oficinas, foram realizadas no Polo de Educação Superior a Distância de Nova Friburgo, que faz parte do Consórcio CEDERJ' e do Sistema Universidade Aberta do Brasil (UAB)², localizado na região serrana do estado do Rio de Janeiro. A elaboração dos trabalhos com a horta começou no primeiro semestre de $2015 \mathrm{com}$ a escolha do terreno, que precisava apresentar características específicas, como ser plano, com terra fofa, disponibilidade de água para irrigação, ser longe de sanitários e esgoto, apresentar boa luminosidade e com pouco trânsito de pessoas e animais.

Além das mudas de plantas, foram necessárias algumas ferramentas, como enxada, enxadão, ancinho, sacho, carrinho de mão, regador, colher de jardinagem. A preparação do terreno, antes das oficinas, e a manutenção da horta, após as oficinas, foram realizadas num trabalho conjunto entre estudantes, tutores presenciais do polo e alguns moradores do entorno. Para o plantio, foram escolhidos vegetais (Quadro 1) que apresentam bom desenvolvimento o ano todo, como os temperos, plantas medicinais, raízes, foIhagens e algumas flores ornamentais, de fácil manejo, rápido desenvolvimento e que apresentam regeneração com novos brotos ou que disponibilizem partes do seu caule para o replantio de futuras mudas.

1 Centro de Educação Superior a Distância do Estado do Rio de Janeiro. Disponível em: <https://www.cecierj.edu.br/cederj>. Acesso em: 20 ago. 2020.

2 Ministério da Educação/CAPES. Disponível em: <https://uab.capes.gov.br/uab>. Acesso em: 20 ago. 2020. 
Quadro1: Plantas utilizadas no plantio da Horta Acadêmica do polo EaD de Nova Friburgo.

\begin{tabular}{|c|c|}
\hline Nome popular & Nome científico \\
\hline Azaléia & Rhododendron simsii Planch. \\
\hline Berinjela & Solanum melongena $\mathrm{L}$. \\
\hline Beterraba & Beta vulgares L. var esculenta \\
\hline Boldo & Peumus bodus Molina \\
\hline Brócolis & Brassica oleracea $\mathrm{L}$. Grupo Itálica. \\
\hline Cebolinha & Allium fistulosum $\mathrm{L}$. \\
\hline Cenoura & Daucus carota $\mathrm{L}$. \\
\hline Cravina & Dianthus chinensis $\mathrm{L}$. \\
\hline Couve & Brassica oleracea L. \\
\hline Girassol & Helianthus annuus L. \\
\hline Hortelã & Mentha spicata $\mathrm{L}$. \\
\hline Íris da praia & Neomarica gracilis \\
\hline Lírio & Hedychium coronarium J. Koenig \\
\hline Maria sem vergonha & Impatiens alleriana (Herb.) Sprague \\
\hline Onze horas & Potulaca grandiflora Hook \\
\hline Pimenta & Capsicum sp \\
\hline Salsa & Petrosolium sativum Hoffm. \\
\hline &
\end{tabular}

Com o terreno preparado e as mudas prontas para o plantio, foram organizadas duas oficinas teórico-práticas, cada uma com três horas duração, para os estudantes do curso de graduação de Licenciatura em Ciências Biológicas do polo EaD de Nova Friburgo. Também foram convidados a participar das oficinas os tutores presenciais do polo. A primeira oficina, realizada em outubro de 2015, contou com 14 participantes, sendo 9 estudantes e 5 tutores presenciais. A segunda oficina aconteceu em janeiro de 2016, com 24 participantes, 22 alunos e 2 tutores presenciais. $O$ total de participantes das duas oficinas, portanto, foi de 31 alunos e sete tutores presenciais.

As oficinas de horta acadêmica foram divididas em quatro etapas. Na primeira, foi aplicado um questionário prévio, diferente para cada grupo de participantes - estudantes e tutores - para a coleta de dados. Os questionários eram compostos por perguntas abertas e fechadas, para que os respondentes tivessem a oportunidade de discorrer sobre o tema proposto, registrando o conhecimento/experiência que já possuíam. Na segunda etapa da oficina, trabalhou-se a parte teórica, em que foram abordados temas como o que é uma horta, escolha do terreno, ferramentas, limpeza do terreno, preparo dos canteiros, adubação dos canteiros, plantio, como cuidar da horta e colheita. A terceira parte da oficina foi dedicada a ensinar aos participantes a construir algumas ferramentas, como o regador, que foi confeccionado com vasilhames vazios de sabão líquido (FERNANDES, 2009), colher de jardinagem e sementeiras de material reciclável, como potes de doce, caixas de ovos vazias e copinhos descartáveis (OLIANI, 2013). A quarta etapa foi a atividade prática com o plantio de vegetais. Cada espécie foi identificada pelos participantes, com nome popular, científico, época de plantio e de colheita. Ao final das oficinas, os participantes responderam a outro questionário, que continha perguntas abertas e fechadas com o intuito de avaliar a oficina e discorrer sobre suas percepções. Os comentários, falas e opiniões dos envolvidos, em todas as etapas, foram anotadas em caderneta de campo e utilizadas na análise dos resultados, conforme indicam Kher e Portugal (2015). 
Após as oficinas, foi realizada a manutenção da horta, semanalmente, por um período de seis meses, com a participação de estudantes, tutores, funcionários e moradores do entorno do polo.

\section{Resultados e discussão}

\subsection{Estudantes cultivando o conhecimento e tecendo relações socioambientais}

Uma das questões delicadas de um projeto como esse é a parte financeira, como bem apontam Morgado e Santos (2008). Na proposta aqui descrita, com a ajuda dos parceiros, o projeto gastou $\mathrm{R} \$ 84,50$, sendo $\mathrm{R} \$ 50,00$ na compra de ferramentas e utensílios para manutenção da horta e mudas das plantas e $\mathrm{R} \$ 34,50$ para o preparo das oficinas. A busca por parceiros, o tamanho da horta e a utilização de produtos recicláveis foi o diferencial de trabalhos como o de Martins (2015), que gastou uma quantia de $\mathrm{R} \$ 8.500,00$ na implementação de uma horta em uma escola pública do Rio de Janeiro.

A partir da análise das respostas dos estudantes ao questionário, pôde-se verificar que, sobre a complexidade da implantação de uma horta, a maioria dos respondentes considerou de dificuldade regular (51\%), enquanto $29 \%$ consideraram difícil, e $20 \%$ consideraram fácil. Sobre as contribuições pedagógicas de uma horta, $100 \%$ dos estudantes afirmaram que esta pode contribuir para o processo de ensino-aprendizagem.

Os alunos participantes, ao opinarem sobre os possíveis problemas na implementação de uma horta em instituições de ensino, ressaltaram dificuldades, como a falta de conhecimento técnico na estruturação de projetos até a questão de planejamento e organização pedagógica, como foi observado nas discussões durante a oficina e na atividade de plantio da horta (Figura 1 - a e b).

Araújo e colaboradores (2013), em seu trabalho sobre a viabilidade de estabelecimento de uma horta comunitária em instituições filantrópicas, relatam que a implementação de uma horta não é difícil. Porém, os autores ressaltam que se faz necessário um planejamento adequado, a fim de que todos os procedimentos estejam de acordo com a instituição. Além disso, os conteúdos a serem abordados devem se adequar ao perfil dos participantes, para, assim, realizar um trabalho em conjunto entre professores, alunos e comunidade, de forma exitosa.

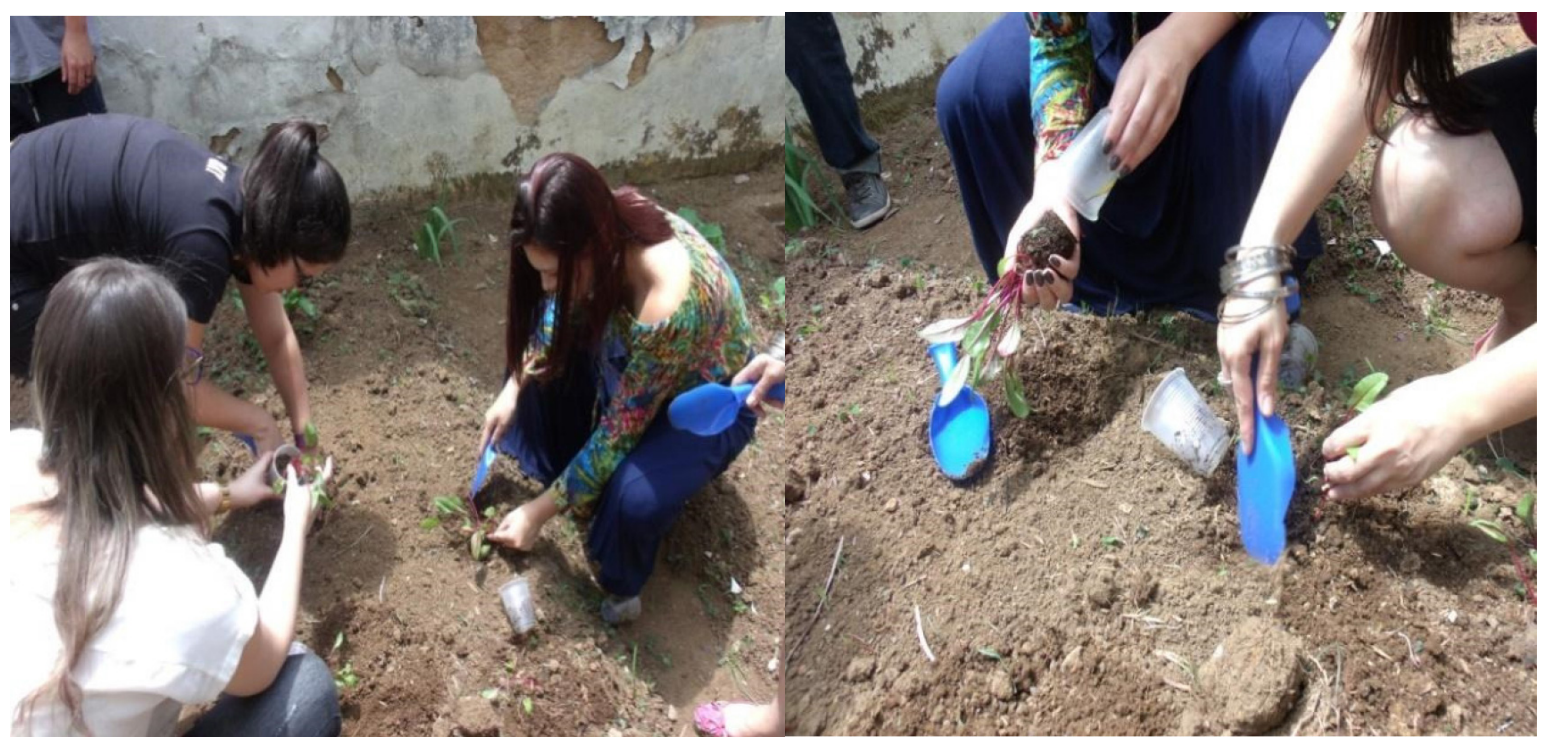

Figura 1(a e b): Plantio de mudas de beterraba pelos participantes.

Fonte: A autora (janeiro/2016). 
Todos os participantes da oficina declararam que construir uma horta pode contribuir para o processo de ensino-aprendizagem. Este fato foi discutido por Cordeiro, Costa e Murata (2014), com o uso de uma horta como ferramenta didática na educação infantil. Estes autores relatam que o fato de os alunos estarem envolvidos diretamente com o processo prático da construção da horta contribuiu para uma melhor compreensão do conteúdo escolar. Além disso, houve discussões de temáticas ambientais e qualidade de vida que extrapolaram as expectativas iniciais. Estas observações também foram verificadas na aplicação das oficinas e no decorrer do plantio e manutenção da horta do Polo EaD, pois este se tornou um espaço de discussões socioambientais. Diálogos que, para alguns alunos, eram restritos aos fóruns acadêmicos foram realizados na prática, durante a rega e plantio da horta. Nossos resultados indicam que a horta pode ser um canal de discussões férteis, também no ensino superior a distância.

Outra questão respondida pelos alunos participantes versava sobre a viabilidade de manter uma horta no Polo. Todos concordaram que é viável e apontaram sugestões para a continuidade do projeto, como a Aluna A, que disse: "Sim, acredito que se todos os alunos se unirem e dividirem as tarefas, a horta será um incentivo ao conhecimento ao longo de todo o curso." A aluna B ratifica a ideia de que os estudantes sejam responsáveis pela horta: "Sim. É viável, contando com a colaboração dos alunos e com o curso de Biologia, se torna um espaço de aprendizado."

As respostas das estudantes A e B vão ao encontro dos relatos de Fernandes (2009), que disse ser possível manter uma horta nas instituições de ensino e que o trabalho organizado em equipe, com a presença do coletivo na resolução de questões de cunho ambiental, pode ser a chave para a solução de pequenos ou grandes problemas locais. Kher e Portugal (2015) registram que as hortas são, antes de qualquer coisa, espaços propícios à socialização e integração de saberes, tanto acadêmicos quantos sociais. Mesmo que nas hortas não seja produzido nada, ainda assim existe a possibilidade de se construir conhecimento, ou melhor, cultivar o conhecimento e tecer relações socioambientais (ROCHA, 2009).

No início da oficina, alguns participantes estavam ansiosos e foi constatada a pouca experiência em relação ao contato direto com o plantio e a insegurança, quando questionados sobre conteúdos estudados por eles em disciplinas como ecologia ou botânica. Outros alunos demonstraram um conhecimento informal, no qual relataram ter adquirido no convívio familiar. A pouca experiência com o manejo da terra de alguns alunos foi provavelmente decorrente da vivência na zona urbana, pois apenas seis alunos das oficinas residiam em área rural. Porém, todos os participantes se mostraram satisfeitos e interessados com a oportunidade de vivenciar o projeto e pelo fato de que a participação na oficina pudesse auxiliar na sua trajetória acadêmica (Figura 2).

Foi solicitado aos estudantes que respondessem se consideravam relevante uma horta como ferramenta didática, e todos concordaram que esta é importante e facilita a compreensão teórica em todos os níveis de ensino. Além disso, ressaltaram a possibilidade de a horta ser usada como fonte de pesquisa, e ser aliada de sua futura prática docente: "A horta traria os estudantes EaD ao Polo, facilitando sua interação, seu aprendizado, além de um bom exemplo para que possam desenvolver projetos como estes, quando forem professores, com seus discentes" (Aluno W). 


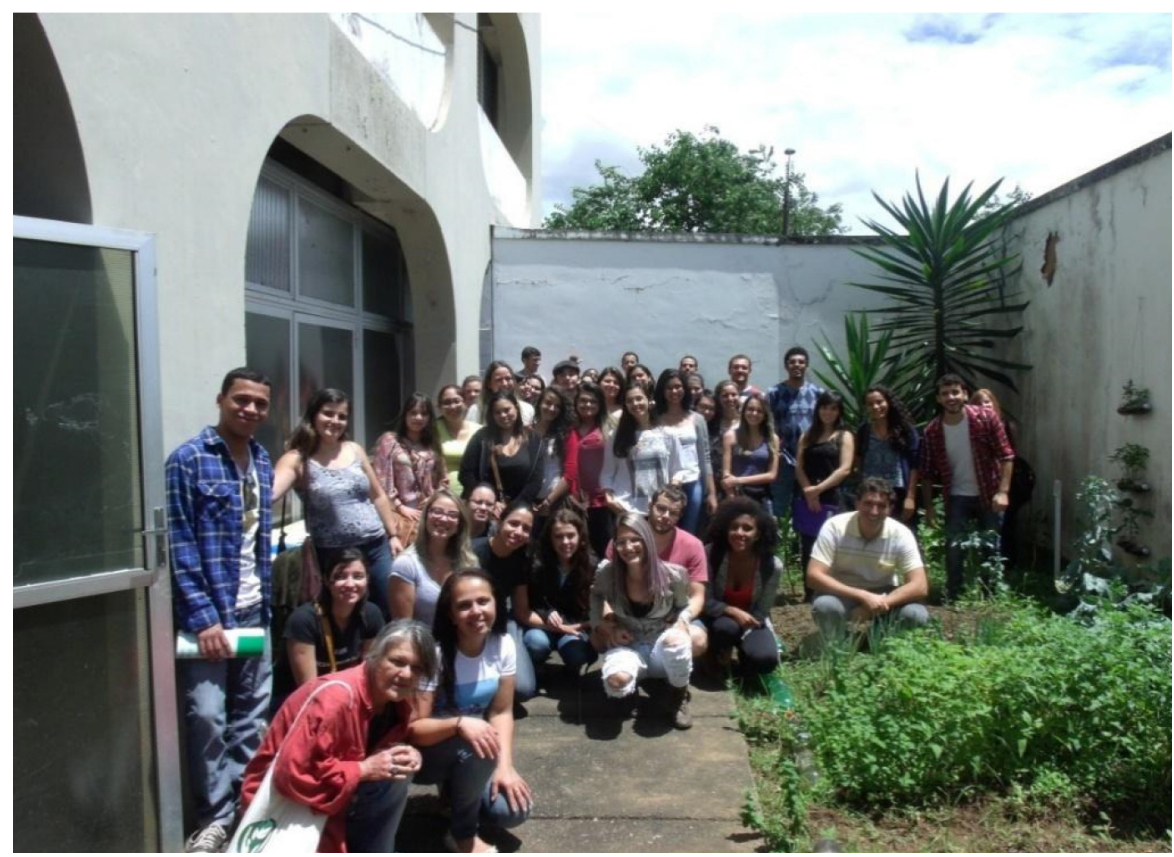

Figura 2: Alunos e tutores presenciais participantes da oficina.

Fonte: A autora (janeiro/2016).

Para os estudantes entrevistados, a participação no projeto da horta acadêmica pode aumentar o sentimento de pertencimento ao polo/universidade. Este estímulo a estar mais presente no polo é saudável e apontado como importante para a diminuição da evasão na EaD (LACERDA e ESPÍNDOLA, 2013; SOUZA, MAZIN e LACERDA, 2015). Além disso, a horta é vista por estes alunos, como passível de ser usada como atividade fora dos muros da universidade, de modo a cooperar para a semeadura de futuras práticas docentes, em concordância com as observações obtidas por Lemos et al. (2018).

O aprendizado pode ser comparado a uma boa refeição: "quanto mais atraentes estiverem os pratos, com mais vontade se deseja saboreá-los" (TIBA, 2005). Neste sentido, a multiplicidade de possibilidades didáticas que uma horta pode oferecer, permeadas por várias questões socioambientais, fez com que os estudantes percebessem a horta com uma "boa refeição", por ser atraente nas perspectivas acadêmicas e de ensino-aprendizagem. Trazer para o Polo EaD toda a gama de atividades inter/multi/transdisciplinares que uma horta propicia é tornar aquele local como um espaço de convívio social, onde muitas pessoas ensinam, aprendem e trabalham. Nesse sentido, e em conformidade com Ortega (2008), os programas de educação envolvendo as hortas podem ter importante repercussão, beneficiando os estudantes e tornando-os exemplos positivos para suas famílias, e para a comunidade na qual estão inseridos, refletindo na sua formação acadêmica.

\subsection{Tutores no plantio da horta}

Nas duas primeiras questões do questionário elaborado para os tutores foi perguntado se, na opinião dos respondentes, uma horta poderia auxiliar na aprendizagem em um curso superior a distância e se eles conseguiriam desenvolver uma aula prática em uma horta. Todos responderam positivamente. Também foi positiva a resposta à pergunta discursiva "Você acha viável manter uma horta do Polo?" que foram acompanhadas de alguns comentários como: "Seria uma excelente oportunidade de aproveitamento de espaço e contaria com a participação de alunos e tutores (Tutor A)" e "Sim, pois o polo apresenta espaço adequado para esta finalidade; além disso, poderia haver cooperação de tutores e alunos (Tutor B)." 
Os resultados obtidos com os tutores concordam com as respostas dos estudantes no que se refere à contribuição da horta para o ensino-aprendizagem e a viabilidade de sua manutenção no Polo através da cooperação entre estes atores da EaD. A importância desse envolvimento cooperativo entre tutor e aluno é destacada como um ponto para o sucesso da EaD (VILLARDI e OLIVEIRA, 2005). Para isso, são necessários a valorização e o esclarecimento sobre o papel do tutor presencial, para que a concepção da ideia do aluno aprendendo de forma solitária na EaD não seja ampliada.

No questionário dos tutores foi, ainda, elaborada a seguinte pergunta: "É possível envolver os alunos na manutenção de uma horta?". Todos os respondentes disseram que sim, e este resultado foi se descortinando com o passar dos meses. Houve vários relatos orais onde os alunos expressaram entusiasmo em frequentar o polo para a manutenção da horta, assim como o orgulho e satisfação de terem trabalhado em equipe. A dinâmica em torno da horta trouxe para o polo a perspectiva de facilitar e potencializar as ações dos tutores. Este agente, que necessita de maior representação acadêmica nas instituições em que atua, tem como uma de suas funções apoiar as atividades pedagógicas para que o estudante se sinta parte de um ambiente acadêmico, mesmo que fisicamente longe de um campus universitário (COSTA e KNUPPEL, 2014). Em diversos momentos, tanto nas oficinas quanto na manutenção da horta, foi observado diálogo, que permeou relações de confiança e discussão de conteúdos extracurriculares, ao mesmo tempo em que, por meio dessas interações, os tutores se posicionaram no contexto de produção de conhecimento através da prática e do envolvimento com os estudantes.

\subsection{Semeando parcerias}

O projeto da horta foi apresentado à comunidade acadêmica interna e à população do entorno do Polo, com o intuito de conquistar parceiros que acreditassem no sucesso da proposta e que pudessem ajudar de alguma forma. A busca por parceiros foi fundamental, pois ocorreu o envolvimento do coletivo no projeto, em um espaço acadêmico, possibilitando a troca de saberes. A mãe de uma aluna foi um exemplo, que, ao ser informada sobre a atividade, colocou-se à disposição para contribuir com seus conhecimentos sobre a poda e colheita de vegetais presentes na horta, o que permitiu a troca e a sensibilização sobre os problemas socioambientais da região. Com estas parcerias conseguimos ajuda com a doação de mudas e mão de obra na preparação do terreno para o plantio, além da manutenção da horta, no período pós-oficina. Esta participação de voluntários, tanto da comunidade interna quanto da externa ao Polo, fez com que a horta atingisse outro patamar, além do ensino e pesquisa: uma ação de extensão universitária. A valorização de atividades desta natureza reforça a indissociabilidade universitária (FORPROEX, 2012).

A manutenção de hortas em instituições de ensino é possível quando há intenso planejamento e dedicação de equipes que se alternam no cuidado com a terra (FERNANDES, 2009). Um dos resultados mais proeminentes deste trabalho foi o envolvimento e a dedicação de diversos atores na manutenção da horta, como explícito na Figura 3 (a e b), que apresenta a horta seis meses após a realização das oficinas. 


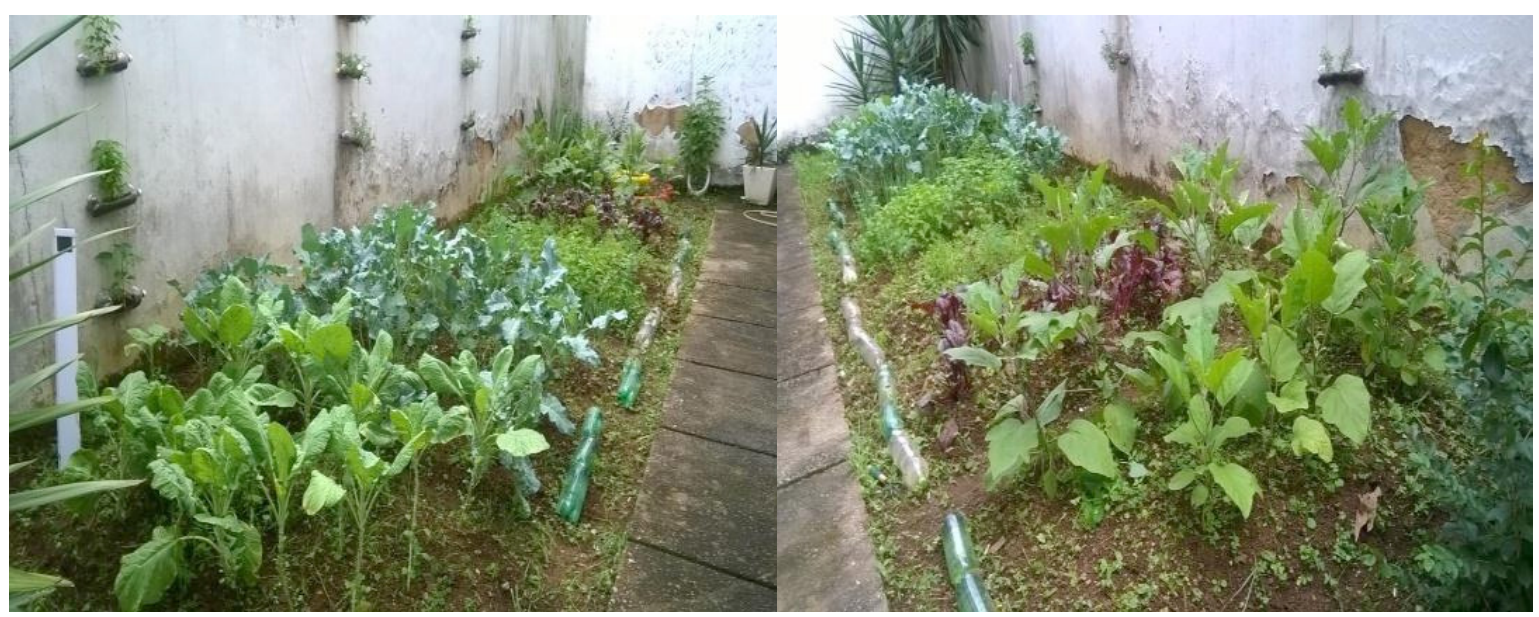

Figura 3 (a e b): Horta no Polo EaD Nova Friburgo após 6 meses do plantio/oficina.

Fonte: A autora (julho/2016).

Assim como o solo de uma horta que, para o bom crescimento das plantas, necessita ser permeável à água, o envolvimento de todos os agentes na construção e manutenção da horta foi possível graças à permeabilidade educativa (GONZALES, 2004). A idealização deste projeto de horta no polo EaD de Nova Friburgo percolou ideias, que foram plantadas e colhidas em trabalhos de ensino, pesquisa e extensão posteriores (LEMOS et al., 2018; LUGON, COSTA e LACERDA, 2018; LUGON, LACERDA e SABA, 2019). Estes trabalhos trazem resultados exitosos, com reverberações socioambientais e de educação ambiental, que ultrapassam os muros do polo em outros contextos de usos da horta acadêmica.

Entendemos, como preconizado por Oliveira (2004), que a educação deve ser vista como uma prática social ligada à formação de valores e práticas do indivíduo para a vida social, com a possibilidade de ir em direção a uma maior autonomia, liberdade e diferenciação. Nossos resultados explicitam a horta como mais do que um lugar, um macro "equipamento" didático, que, quando utilizada adequadamente, potencializa a convivência social e o aprendizado no ensino a distância. Lacerda e Oliveira (2017, p. 313) apontam para "a pluralidade dos polos e suas invenções cotidianas, invenções estas que alteram as propostas curriculares oficiais" e que contribuem para a "construção dos currículos de formação de professores dos cursos oferecidos na modalidade semipresencial". Nessa linha, defendemos que os polos e, mais especificamente, a horta acadêmica, se constituam como "laboratórios a céu aberto, um lócus privilegiado de produção de conhecimentos".

\section{Considerações finais}

Todos os envolvidos no projeto da horta chegaram ao consenso que uma horta é viável como recurso didático no ensino superior a distância, pois possibilita a compreensão teórico-prática de temas abordados no curso de licenciatura. Logo, esta se torna um laboratório de aulas práticas a céu aberto, com inúmeras possibilidades didáticas para alunos e tutores, além de ser um local de reminiscência, tendo significado socioambiental.

O trabalho desenvolvido teve como marca o entusiasmo, percebido em diversos atores que frequentaram o polo, em outros horários fora das atividades acadêmicas oficiais, para a manutenção da horta, com o auxílio dos moradores do entorno. $O$ contato com estes diversos parceiros ajudou também na viabilidade econômica do projeto. Constatamos que é exequível a elaboração e manutenção de uma horta em uma instituição de ensino superior a distância, e que plantar, semear, cultivar, regar, adubar e colher são práticas que nos ajudam a vivenciar a indissociabilidade das atividades de ensino, pesquisa e extensão. 
A convivência social permeada na horta acadêmica possibilitou um ambiente acolhedor, se caracterizando como um macro "equipamento" didático. Desta forma, sugerimos a utilização de projetos desta natureza em espaços dos polos de apoio presenciais. Além disso, ações de investigação continuada na mesma instituição, com a horta, e de averiguação de como estes projetos podem ter diferentes reverberações com outros agentes educacionais são necessárias.

\section{Referências Bibliográficas}

ARAÚJO, A. M. et al. Avaliação da viabilidade da implementação de horta comunitária em instituições filantrópicas por meio de projetos de extensão. VI Semana de Ciência e Tecnologia IFMG - campus Bambuí, VI Jornada Científica 21 a 26 de outubro de 2013. Disponível em: <https://bambui.ifmg.edu. br/jornada_cientifica/2013/resumos/agronomia/4.pdf>. Acesso em: 20 ago. 2020.

CAPRA, F. Alfabetização ecológica: a educação das crianças para um mundo sustentável. São Paulo: Editora Pensamento/Cultrix, 2005.

CORDEIRO, J. C. S.; COSTA, A. C. G.; MURATA, A. T. Utilização de horta vertical como ferramenta pedagógica para educação ambiental em uma escola pública de Pontal do Paraná. Revista Educação Ambiental Em Ação, v. XIII, n. 50, 2014. Disponível em: <http://revistaea.org/pf.php?idartigo=1936>. Acesso em: 7 jul. 2015.

COSTA, M. L. F.; KNUPPEL, M. A. C. As representações sociais do trabalho do tutor presencial: limites e possibilidades. Educar em Revista, Curitiba, Brasil, Edição Especial, n. 4, p. 191-209, 2014. Editora UFPR.

CRIBB, S. L. S. P. A horta escolar como elemento dinamizador da educação ambiental e de hábitos alimentares saudáveis. In: VI Encontro Nacional de Pesquisa em Educação em Ciências. Florianópolis, 2007. Anais [...], Florianópolis: UFSC, p. 1-10 (287), 2007. Disponível em: <http://abrapecnet.org.br/ atas_enpec/vienpec/CR2/p287.pdf>. Acesso em: 1 ago. 2015.

CRIBB, S. L. S. P. Contribuições da educação ambiental e horta escolar na promoção de melhorias ao ensino, à saúde e ao ambiente. REMPEC - Ensino, Saúde e Ambiente, v.3, n. 1, p. 42-60, Abril 2010.

FERNANDES, M. C. Orientação para implantação e implementação da horta escolar. $3^{\circ}$ edição. Brasília: Ministério da Educação, 2009.

FORPROEX. Política Nacional de Extensão Universitária. Manaus: FORPROEX, 2012. Disponível em: <http://www.renex.org.br/documentos/2012-07-13-Politica-Nacional-de-Extensao.pdf>. Acesso em: 20 mar. 2020.

GONZALES, M. A arte da sedução pedagógica na tutoria em Educação a distância. In: $11^{\circ}$ Congresso Internacional de Educação a distância, ABED, Salvador, Bahia, 2004. Anais [...], Salvador, 2004. Disponível em: <http://www.abed.org.br/congresso2004/por/htm/001-TC-A1.htm>. Acesso em: 7 jul. 2015.

KHER, A. L. K.; PORTUGAL, A. S. Horta escolar: cultivando o ensino de ciências. Revista Aproximando, v. 1, n. 1, p.1-10, 2015.

LACERDA, F. K. D.; ESPINDOLA, R. M. Evasão na Educação a Distância: um estudo de caso. Revista EaD em Foco, v. 3, n. 1, p. 96-108, 2013.

LACERDA, F. K. D.; OLIVEIRA, I. B. Os polos de apoio presencial no estado do Rio de Janeiro: que espaços tempos são esses? Em Rede. Revista de Educação a Distância, v. 4, n. 2, p. 303-316, 2017. 
LEMOS, E.S. et al. A importância da extensão universitária na formação docente: uma experiência no curso semipresencial de Ciências Biológicas. In: V Encontro Nacional de Ensino de Ciências e do Ambiente, Niterói, Rio de Janeiro, 2018. Anais [...].Niterói/RJ: UFF, 2018, p.1-10.

LUGON, C. T.; COSTA, M. S.; LACERDA, F. K. D. Viver Jardim: Aprendendo e ensinando com as plantas. In: V Encontro Nacional de Ensino de Ciências e do Ambiente, Niterói, Rio de Janeiro, 2018. Anais [...]. Niterói/RJ: UFF, 2018, p.1-10.

LUGON, C. T.; LACERDA, F. K. D.; SABA, C. C. A. N. Jardinando, ensinando e aprendendo: uma experiência de extensão em um polo EaD do Rio de Janeiro. In: XVI Congresso Brasileiro de Ensino Superior a Distância/ V Congresso Internacional de Educação Superior a Distância. Teresina, Piauí. 2019. Anais [...]. Teresina, Piauí: UFPI, 2019, p.1-10.

MARINO, A. L.; PASSOS, J. F.; MAGALHÃES, A. F. Redes sociais como mecanismos de otimização no processo de educação a distância (EaD). In: SILVA, A.; ROCHA, H.; MOURA, G.; OLIVEIRA, J. A. Gestão e Tecnologia na Educação, v. 1, Belo Horizonte, MG: Poisson, 2018, p. 30-41.

MARTINS, T. S. L. Educando com a horta escolar. Eco do bem. 2015. Disponível em: <https://ecodobem. com.br/projetos/educandocomahortaescolar/>. Acesso em: 08 abr. 2015.

MORGADO, F. S.; SANTOS, M. A. A. A horta escolar na educação ambiental e alimentar: Experiência do Projeto Horta Viva nas escolas municipais de Florianópolis. EXTENSIO, Revista Eletrônica de Extensão, UFSC,v. 5, n. 6, p. 1-10, 2008.

NUÑEZ, M. E. C. Tendencias en el diseño educativo para entornos de aprendizajedigitales. Revista Digital Universitaria, v. 5. n. 10, p. 2-26, 2004.

OLIANI, S. Plásticos, como se dá a reciclagem e no que se transforma? ECycle, 2013. Disponível em: <http://www.ecycle.com.br/component/content/article/35/711-plasticos-como-se-da-a-reciclagem-eno-que-se-transformam.html> Acesso em: 08 mar. 2015.

OLIVEIRA, I. B. (Org.). Alternativas emancipatórias em currículo. São Paulo: Cortez Editora, 2004.

ORTEGA, M. A. O trabalho em grupo como estratégia para o desenvolvimento do projeto Horta: experiência vivenciada no ensino de Biologia. 2008. 116 f. Dissertação (Mestrado em Ensino de Ciências e Matemática) - Universidade Cruzeiro do Sul, São Paulo, 2008.

ROCHA, A. P. Horta escolar: A Interseção entre educação ambiental e o ensino de Ciências. 2009. 101 f. Monografia (Licenciatura em Ciências Biológicas) - Universidade Federal Fluminense, Niterói, Instituto de Biologia, 2009.

SILVA, R.F. et al. Horta Agroecológica como Ferramenta de Ensino e Educação Ambiental. In: XIII Jornada de ensino, pesquisa e extensão. UFRPE: Recife, 2013. Anais [...]. Recife: UFRPE, p. 1-3, 2013. Disponível em: <http://www.eventosufrpe.com.br/2013/cd/resumos/r0416-1.pdf>. Acesso em: 14 fev. 2021.

SOUZA, M. P.; MAZIN, D. P.; LACERDA; F. K. D. Evasão na educação a distância: uma análise do curso de Licenciatura em Geografia no Polo EaD de Nova Friburgo/RJ. Revista Tessituras, n. 6, 2015, p. 148-162.

TIBA, I. Ensinar aprendendo: como superar os desafios do relacionamento professor-aluno em tempos de globalização. São Paulo: Gente, 2005.

VILLARDI, R; OLIVEIRA, E. G. Tecnologia na educação: uma perspectiva sociointeracionista. Rio de Janeiro: Dunya, 2005. 